\title{
Factors influencing recovery in opioid substitution treatment: a systematic review and thematic synthesis
}

Victoria Carlisle ${ }^{1,2,3}$; Olivia M Maynard ${ }^{1,2}$; Prianka Padmanathan ${ }^{4}$; Kyla Thomas ${ }^{4}$; Matthew Hickman $^{4,5}$; Joanna Kesten ${ }^{4,5,6}$

${ }^{1}$ Tobacco and Alcohol Research Group, School of Psychological Science, University of Bristol

${ }^{2}$ MRC Integrative Epidemiology Unit, University of Bristol

${ }^{3}$ NIHR School for Public Health Research., University of Bristol

${ }^{4}$ Population Health Sciences, Bristol Medical School, University of Bristol

${ }^{5}$ The National Institute for Health Research Health Protection Research Unit in Behavioural Science and Evaluation at University of Bristol

6 The National Institute for Health Research Applied Research Collaboration West (NIHR ARC West) at University Hospitals Bristol NHS Foundation Trust, UK

\section{Declarations of Interest: None.}

Word count (excluding abstract, tables and figures): 4478 


\section{ABSTRACT}

\section{Background and Aims}

Recovery outcomes for opioid substitution treatment are poorer than those for alcohol and other drugs. In order to understand why this is and to synthesise the findings of a large number of qualitative studies, we conducted a systematic review and thematic synthesis to understand facilitators of and barriers to recovery from opioid dependency.

\section{Methods}

Electronic databases (Pubmed, PsychInfo, CINAHL and Embase) were searched. English language studies exploring the views of adult service user and stakeholders with experiences of opioid substitution treatment were considered for inclusion. Included studies were inductively analysed using thematic synthesis. During analysis, the socioecological model was selected as an analytical framework for organising and making links between themes as it captured the complexity of the topic well.

\section{Results}

From 3646 screened papers, we included 37 studies reporting the views of 1212 staff and service users. Studies highlighted complex interactions between factors influencing recovery across the five levels of the socioecological model (intrapersonal, inter-personal, organisational, community and policy). Early life experiences of trauma were common; lack of support (both psychological and social) was also a recurring theme resulting in feelings of disconnection and isolation. Stigma played a particularly important role in an individual's capacity to recover from opioid dependency and cut-across all levels of the socioecological model.

\section{Conclusions}

Interventions targeted at the individual level fail to take account of the complexity of recovery within opioid substitution treatment and may ignore the complex socio-political context that service users and services exist within. Stigma permeates all levels of the opioid substitution treatment system; we suggest that addressing this is likely to improve healthcare encounters, help-seeking, increase access to social support and facilitate community reintegration for individuals receiving opioid substitution treatment. 


\section{FACTORS INFLUENCING RECOVERY IN OST}

\section{Keywords}

OST, opioid, opioid substitution treatment, qualitative systematic review, thematic synthesis, opioid use disorder, opioid dependency, drug treatment, socioecological model, stigma, pharmacy, primary care. 


\section{INTRODUCTION}

In the United Kingdom (UK), there are an estimated 340,000 high-risk opioid users (1).

Opioid substitution treatment (OST) comprises a pharmacological component (methadone or buprenorphine), combined with psychosocial support, and is the first line treatment for opioid dependency in the UK and elsewhere. There is a strong evidence base for the effectiveness of OST, with multiple benefits including a reduction in the transmission of blood-borne viruses such as Hepatitis $\mathrm{C}$ virus, human immunodeficiency virus (HIV) (2) and a reduction in drug related deaths $(3,4)$. However, such benefits occur only during OST and may be undermined if treatment is not delivered as intended, i.e. for prolonged periods and with discharge after planned taper from medications (5). This is a particular issue in England $(5,6)$, where only $22 \%$ of all opiate clients were discharged 'successfully' between 2018 and 2019 (defined as mutually-agreed planned exit with no re-presentation to treatment services within six months).

A 2013 qualitative review sought to understand the barriers to 'recovery' amongst long-term OST clients (7). Recovery was conceptualised as a process rather than abstinence from opioids. Barriers included fear of withdrawal symptoms, difficulties with social integration and a resurgence of painful emotions during detox. This review did not explore facilitators of recovery, which are important when considering intervention development to improve treatment outcomes. Furthermore, the political and treatment landscape has changed since 2013, including the publication of an updated UK Drugs Strategy in 2017 (8), in which the focus of treatment was shifted towards recovery. This change may result in service users feeling pressured to leave treatment before they feel ready. Additionally, the explosion of the 'opioid crisis' in the United States (9) has resulted in a rapid expansion of OST provision there.

In this review we synthesise the qualitative literature exploring service user and stakeholder experiences of recovery. In doing so, we provide a timely update to the 2013 review (7) and expand the scope to include facilitators of recovery and all durations of treatment. 


\section{FACTORS INFLUENCING RECOVERY IN OST}

\section{METHODS}

The review protocol is published elsewhere (10). We synthesised qualitative studies to obtain a rich, in-depth insight into the challenges of recovering from opioid dependency.

\section{Inclusion Criteria}

\section{Participants}

We considered studies for inclusion that reported the experiences of adults currently or previously receiving OST for opioid dependency and/or the experiences of stakeholders (staff, policymakers, family members or carers).

\section{Outcomes}

Experiences of recovery and treatment completion within the context of OST in primary care or community treatment services.

\section{Studies}

We considered for inclusion all peer-reviewed qualitative studies or qualitative aspects of mixed-methods studies from any country.

\section{Exclusion Criteria}

Only English language studies were included. We excluded studies with a focus on pregnant women, young people or prisoners, as there are marked differences in treatment provision for these populations. We excluded studies published prior to 1999 to focus on recovery experiences most relevant to current drug policies.

\section{Search Strategy}

PICOS (Population, Intervention, Comparison, Outcomes, Study design) was used to develop a Boolean logic search strategy. This method maximises both sensitivity and specificity in qualitative syntheses (11). We searched Medline, CINAHL, Embase and PsychInfo electronic databases. A University of Bristol expert subject librarian assisted in identifying databases, Medical Subject Headings (MeSH) and keywords, and in developing a comprehensive search strategy, (table S1 \& (10). Qualitative search terms were developed after consulting the ISSG Search Filters Resources (12). We hand-searched reference lists and relevant journals. 


\section{Study selection}

References were managed using Endnote reference management software and articles screened with Rayyan QCRI. All searches were completed by $7^{\text {th }}$ January 2019. VC and PP screened titles and abstracts in duplicate and discussed any disagreements. Key information (as shown in Table 1) was extracted for each paper, and VC considered articles for inclusion based on the criteria above, by reading the results and discussion sections in detail.

\section{Qualitative Synthesis}

Although we planned to analyse the results using meta-ethnography (13), many of the studies were too conceptually 'thin' $(13,14)$. Instead, thematic synthesis $(15)$ was chosen as it offers a transparent way of identifying patterns in data, whilst still 'going beyond' the findings of original studies to generate new understandings. Thematic synthesis is also particularly useful for informing intervention development (15).

Using QSR NVivo, VC inductively coded the results and discussion sections including relevant quotes from participants and primary author interpretations, remaining close to the meanings of the primary studies. Semantically related codes were grouped to produce 'descriptive' themes. Finally, we moved beyond the findings of the primary studies to develop 'analytical' themes. The range of concepts captured by the descriptive themes was broad and represented facilitators and barriers in the individual, social, environmental and political spheres. At this stage, we therefore selected the socioecological model, with its five levels; 1) intrapersonal; 2) interpersonal; 3) institutional; 4) community and 5) policy (16), as an analytical framework for organising and making links between descriptive themes. This framework allows for mapping and consideration of complex interacting influences on behaviour and is increasingly used for developing interventions (17-19). Analytical themes were finalised through discussions between JK and VC.

\section{RESULTS}

\section{Search results}

Database searching identified 4,927 records, with seven additional records located from other sources. After de-duplication, we screened the titles and abstracts of 3,646 studies. At this stage, 3,563 were excluded with reasons (see Figure 1) leaving 37 papers of 34 studies. [INSERT FIGURE 1 HERE] 


\section{FACTORS INFLUENCING RECOVERY IN OST}

\section{Study and participant characteristics}

Of the included studies, 28 reported views of service users only, 3 reported only stakeholder views and 6 reported both, giving a total of 1212 participants (981 service users and 231 stakeholders). Most studies were conducted in the UK $(n=10)$ or USA ( $n=9)$, with others carried out in Ireland ( $n=5)$, Canada $(n=3)$, Australia ( $n=3)$, Denmark (2), Norway $(n=2)$, Belgium (1), Italy ( $n=1)$ and Sweden $(n=1)$. Twenty-five of the studies included here were published after searches were completed for the 2013 review (7). Table 1 presents the characteristics of the included studies. The population of OST service users was heterogenous: while some were still using heroin in addition to their OST script and lacked stability, others had significant stability in their lives, such as employment and housing.

\section{[INSERT TABLE 1 HERE]}

\section{Socioecological factors influencing recovery}

Descriptive themes at each level of the socioecological model are shown in Figure 2. Key findings are described below with all descriptive, analytical themes and sub-themes detailed in table $\mathrm{S} 1$.

\section{[INSERT FIGURE 2 HERE]}

\section{Intrapersonal}

Normality, stability and routine were identified as important concepts by service users. Some welcomed the stability that OST medications provided in contrast to the chaos of seeking and taking illicit opioids $(21,23,24,29,31-33,35,37)$, whilst others struggled to adjust to the constraints of 'normal' life with the rules and routines associated with treatment $(24,25,27$, 39):

Recovering heron users want to be normal and yet they also want to retain their individuality, they aspire to the mundane and yet they are anxious that this is also boring, they want to comply with social norms and conventions and yet they want to retain their distinctiveness [primary authors' interpretations] (27) p.186. 
Several studies described accounts of traumatic experiences, particularly during childhood (20-23):

Childhood adversity was an exceptionally common occurrence across the interviewees [primary authors' interpretations] (21) p.29.

And these adversities often continue into adulthood:

"I lost two children in 9 days. My son, he hung himself in prison, three days left in his sentence. My daughter committed suicide 9 days later. She went out, bought Xanax (alprazolam), and took the whole lot and she took about nine bags of heroin as well and just threw herself off the bridge. Afterwards, I tried to kill myself." [service user] (21) p.6.

Unresolved underlying issues such as these appear to be a key barrier to recovery and are particularly relevant during tapering and detox from OST medications when emotions that have been numbed for long periods, often return with intensity:

"When you're coming off your methadone, you become very, well, for me anyway I become very emotional, you know, you start thinking a lot, your feelings come back. Things hit you and you're like 'oh God, I'd forgot about that', and yeah, I'm very raw and emotional" [service user] (24). p.349.

OST medications should be delivered in tandem with psychosocial support, however treatment services may not be providing the type of support that service users need during detox, placing more emphasis on stopping drug use than resolving underlying issues (24-28)"

"I do feel that the services tend to treat the symptoms not the cause hugely" [service user] (29) p.236.

The included studies show that, although abstinence is not a goal for all services users, with 'on-top' use of heroin relatively common (20,26,29-31). As described above, many welcome the stability provided by OST to be able to stop using heroin and regain a sense of normality and routine $(21,23,24,29,31-33)$. However, the next steps towards 'recovery', and for some, 


\section{FACTORS INFLUENCING RECOVERY IN OST}

abstinence, are more challenging. To achieve this, clients must regain a sense of self $(24,25,29,34)$, rebuild relationships $(25,35)$ and potentially try to gain employment, whilst negotiating the issue of employment interfering with the collection of medications and appointments for services such as counselling $(28,29)$."Filling the void" (31) that heroin occupied appears to be particularly challenging:

“Recovery is an individual thing, recovery isn't just coming off methadone, it's a hell of a lot more than that, it's about occupying time, trying to get back into society, trying to get back to the normal things, it's filling the void that the heroin and everything that comes with the heroin use, the friends, parties" [service user] (31) p.66.

For some, spirituality is an important aspect of recovery and may increase feelings of stability (36), bolster relapse prevention efforts (37) or facilitate trust building (38). However, for others religious aspects of 12-step programmes are aversive and may prevent individuals from accessing an important source of social support:

"The NA and AA though I'm not really down with that. I had the church shoved down my throat all my life. I don't want it anymore" [service user] (28) p.27.

\section{Inter-personal}

Several studies described experiences of relationship breakdowns with family and friends prior to entering treatment $(20,25,31,37,39)$. For many service users, their drug using networks may be the only place they can continue to feel a sense of belonging. There is a tension between a desire to move away from these networks and apprehension about establishing more healthy connections $(22,25,27,31,37)$. Relationships were described as both supportive and stressful; for instance having a partner who is also in recovery may facilitate recovery (29), whilst having family and friends that are still using drugs may perpetuate drug use (21-23,27):

"It happened that I started abusing again. When I went back to Terni [ participant's hometown] I found all my friends, the old ones, and I started again right away. Would you believe it! When you fall back into that crowd, they offer it to you right away and it's over." [service user] (39) p.11. 
Older clients may struggle to trust others and develop social networks due to repeated previous negative experiences of relationships, depriving them of an important source of support in early recovery (22).

When friendships do exist that are supportive and positive, they can override the feelings of disconnection mentioned above and allow individuals to feel 'seen' again:

"Friendship has always been important to me, a good conversation means so much more than whatever form of medication. I can't explain it, but friendship is a sort of recognition for me. It makes me feel I am part of the world again" [service user] (40). p.11.

In an attempt to address social isolation, peer support is often woven into OST programmes; however, service users may be reluctant to receive this type of support, seeing peers as vulnerable to relapse themselves (28)

"Sitting there listening to people tell stories about being sober and knowing that you seen [them] at the pill dealer last week. So, I don't...I'm not going to sit and listen to people lie and try to tell you that they're sober when they're not [service user] (28) p.27.

\section{Organisational}

Client-staff relationships within OST were referred to many times across the studies, with positive relationships allowing service users to feel valued and 'heard'; to be seen as an individual:

\footnotetext{
"It was nice to know that somebody actually looked out for Tracy, not just 'methadone Tracy" [service user] (34) p.456.
}

This relationship can be particularly key as for some, it may be the only interpersonal interaction they have (41). The keyworker role may provide unique challenges for both service users and staff, with staff having to perform multiple roles including 'gatekeeper' of medications and 'monitor' of treatment adherence (42). This may result in service users feeling the need to withhold information in order to secure their medications $(21,25,28,34,42-46)$. The 'monitoring' aspect of the role (for instance, performing drug testing) appeared to be a particular barrier to building trust in client-staff relationships (42): 
FACTORS INFLUENCING RECOVERY IN OST

"Always trying to catch me doing something...How can you talk to somebody like that or tell him something personal...? [service user] (22) p.663.

\section{Community}

For those service users who enter OST with a goal of stopping illicit opioid use, they may find themselves experiencing a chronic feeling of disconnectedness from their communities and wider society. Whilst actively avoiding their drug using networks, they do not yet feel integrated into wider society $(25,27)$. This leaves individuals feeling isolated and lonely $(20,21,25,37,43)$, which in turn results in increased vulnerability to relapse:

"Although many of the participants described the drug scene as rotten and deceitful, they still felt included, respected, and to a certain degree appreciated...In ordinary society, they became no one and were left vulnerable and at risk of seeking the communities where they were recognized and felt a sense of belonging"'[primary authors' interpretations] (25) p.8.

Recovering service users often live in the same communities as they did before they entered treatment and are surrounded by constant social and environmental triggers to use drugs $(26,29)$. Even treatment settings can be a place of danger, with others around them still using, or dealers unscrupulously targeting such locations $(23,31,33,41,45)$ :

"The problem is my clinic is a drone for drug dealers...always getting asked when I leave the clinic, if I want to buy gear [heroin]" [service user] (31) p.66.

Due to this disconnection from community, it is often suggested that service users try to engage in recovery communities such as AA and NA. However, there are barriers to participating in such communities, particularly the aversion to religious aspects of such communities described above. Some service users may be uncomfortable with the "perpetual recovery' focus of 12-step programmes, which tend to reject the notion that one can ever achieve a state of being recovered (28). Such fundamental conflicts between the values of service users and those of recovery organisations may leave large numbers of service users with unmet social needs, further perpetuating feelings of exclusion and isolation:

"I never think about recovery because I cannot see myself not getting high. Like AA and NA, 
they don't want you to drink. They want total abstinence, and I can't see it. I just can't see there being nothing. So I don't think about recovery because I know it doesn't apply to me.

I'm maintaining and doing what I gotta do" [service user] (23) p.407.

Policy

Several studies described a conflict between policy recommendations and what is delivered in practice. This included pharmacies not adhering to guidelines:

"There is a need to uphold standards of privacy in pharmacies. Despite the availability of private rooms for supervision (which are provided in the UK as part of the contractual arrangements that pharmacists have with service commissioners) they are not always used", [primary authors' interpretations] (47) p.70.

Failing to provide such services uniformly, means inconsistency in treatment quality across settings and may result in service users facing additional, unnecessary barriers to recovery. Another study describes experiences of service users being subject to sanctions that are more severe than policy recommends:

“...this[sanction] is not entirely in keeping with the OMT [opioid maintenance treatment] regulations, which allow some abuse of illicit substances on the side. Nevertheless, there were several other participants with similar accounts, where what they regarded as "minor slips" brought on major consequences. It may thus seem as though the user's opinion is that practice is stricter than the regulations allow. " [primary author's interpretations] (25) p.6.

From the perspective of staff members however, such deviations from policy were often the result of doing what they felt was best for service users:

Several participants [General Practitioners] described the national prescribing guidelines as a policing system rather than therapeutic intervention for opiate dependents, with little evidence consulted in the design of these specified guidelines or the evaluation of individual outcomes..." [primary authors' interpretations] (46) p.232.

Other barriers to recovery at the policy level reflected the proliferation of recovery orientated treatment systems. From a service user perspective, such systems may present an unrealistic 


\section{FACTORS INFLUENCING RECOVERY IN OST}

goal of abstinence (23).

\section{Stigma}

Stigma is a cross-cutting concept that permeated all levels of the SEM and was referred to either directly or indirectly in 22 of the 37 included studies. The studies showed that service users are vulnerable to experiencing stigma from a wide range of sources including from pharmacy staff and other customers when collecting OST medications $(44,47-50)$; the GP surgery and other healthcare settings $(21,43,45,50,51)$; from their family and friends (25); from the wider community $(25,27,29,41,43,45)$ and from the government $(27,50)$.

Repeatedly experiencing stigma results in service users fearing judgement from others, which can directly lead to premature detox from OST to avoid further scrutiny (29). This may leave service users vulnerable to relapse and overdose and may prevent them from seeking help from professionals for other health issues $(21,43,51)$. Experiencing stigma can lead to feelings of shame and result in self-stigma - the lowering of one's expectations of self and motivation to change $(25,30,50)$. Self-stigma may also be the driver of service users isolating themselves from others, which perpetuates feelings of exclusion and loneliness (45) - a barrier to recovery. As a result, people may feel that they are not worthy of help:

"You are not born with the choice of diabetes but you are born with the choice of not taking heroin" [service user] (21) p.8.

"We are a plague on society. We really are people who use opioids and shoot up in the alleyways. It's a dirty habit. It's a plague. It's not good. I approve of methadone clinics, but when people say they don't want them beside their houses, I don't blame them"

$$
\text { [service user] (45) p.3. }
$$

At the inter-personal level, one study theorised that social support can cushion the effects of stigma via improved self-esteem:

“...participants with "non-addict" or "functional" self-concepts tended to have higher levels of resources and supportive social relationships...these resources assisted non-addict and functional types to better cope with the stigma associated with methadone use" [primary authors' interpretation](48) p.1876.. 
The pharmacy setting appears to be a particularly strong source of stigma for OST service users; across several studies they reported feeling shame and embarrassment at the way they are looked at by other customers whilst collecting OST medications $(43,44,47,49,50)$.

“... It's still not very private [in the pharmacy] and people can see you from out the back ... people look at you. When they're giving you stuff and you've got to sign for it and drink it and then you leave or you get your take-aways. People look at you funny"

[service user] (49) p.1023.

Service users were ambivalent about whether pharmacies should provide a separate area for supervised consumption and collection of OST medications, with some welcoming the privacy and others feeling that the area signalled to other customers the reason for them being there. A suggestion from a participant in Le \& Braunack-Mayer's (2019) study was for pharmacies to provide a screened area that could be used for any private conversation with the pharmacist, not just OST clients, thereby preserving OST client's privacy and anonymity.

Concerningly, misconceptions about OST medications may infiltrate the legal system as well as the public consciousness:

"He [Judge] said, 'You are substituting with methadone?' I said 'yes'. He said 'You are still using. It is nothing but a substitute for Vicodin'. He said, 'You are still using opiates, so you are still using.", [service user] (37) p.957.

Finally, at the policy level of the SEM, government drug policies can be stigmatising, for instance by portraying OST service users as a homogenous group that is economically unproductive (50).

\section{DISCUSSION}

Key factors that influence recovery within OST and potential intervention targets include stigma, trauma and social support. Critically, these interact and operate at multiple levels (figure 3). 


\section{FACTORS INFLUENCING RECOVERY IN OST}

Experiences of trauma were ubiquitous across the studies $(20,21,23-25,29,30,35,52)$. This trauma often pre-dated drug use, commonly in the form of adverse childhood experiences or 'ACEs' (53), but also continued into adulthood from experiences such as physical and sexual assault and grief $(21,22,54)$. Such experiences, if unresolved, may result in the initiation of opioid use as a form of self-medication (55). Survivors of trauma often report feelings of shame and guilt (56), and if unresolved, the re-emergence of these feelings during tapering and detox may make this stage extremely challenging and could lead back to using drugs to manage the feelings $(24,25,27,28)$. Experiencing repeated trauma is also known to contribute to difficulty in forming and maintaining relationships (57); something reflected in the experiences of service users in the included studies, who also reported experiences of relationships breaking down due to their drug use $(20,22,37,39,58)$.

\section{[INSERT FIGURE 3 HERE]}

Stigma was identified in the majority of studies as a key barrier to recovery in OST as it is omnipresent in the lives of service users. Goffman (59) visualised stigma as inherent in the relationship between the stigmatised and 'normals'. One of the themes we identified 'normality, stability, routine' - reflects the way that such discourses of normality are internalised by service users and can act as both a facilitator and barrier to recovery. For instance a desire for normality and stability may motivate recovery attempts, yet normal life is also seen as boring (27). Our findings reflect the wider literature on the experience of stigma in substance use disorder more generally (60-63) and to opioid users specifically (64$66)$.

Tackling opioid-stigma needs to happen at every level of the system: from empowering service users to understand the effects of stigma and encouraging them to advocate for each other; to educating healthcare staff about the ways in which stigma manifests itself in their interactions with service users; to community outreach programmes that seek to destigmatise OST and reintegrate service users into their communities and finally by addressing stigma at the government level through the adequate funding of mental health and drug treatment services. The pharmacy setting was somewhere that service users felt acutely exposed to judgement from staff and customers $(43,44,47,49,50)$. It is vital therefore that pharmacy staff receive sufficient training to understand the importance of their role in supporting OST service users and the positive and negative effects their interactions may have on individual 
recovery efforts. As experiences of stigma and complex trauma have an inherent relationship with power $(56,67)$, we recommend that service users are empowered in any intervention development work through effective Patient and Public Involvement and co-production (6870).

Other important factors that interact with trauma and stigma in OST are relationship difficulties, isolation and boredom. Service users described how their drug using status has resulted in the breakdown of relationships and how this left them feeling lonely, isolated and disconnected from non-drug using networks $(20,21,25,27,37,43,50)$. This may lead individuals to turn to their drug-using networks where they feel a sense of belonging and acceptance. Service users reported feelings of boredom with 'normal' life, which may be a relapse trigger $(21,29,37,50)$. As social support may buffer the effects of stigma by increasing self-esteem (48) intervention developers and service managers should consider how this can be increased. Whilst peer support or mutual-aid programmes are often recommended as a way of increasing social support for people who use drugs, our findings suggest there may be significant barriers in accessing such support, due to previous negative experiences with such schemes and difficulties in trusting others.

Although not all OST service users will present with complex trauma, many will (71). It is vital therefore that OST is delivered alongside enhanced psychological interventions that address underlying mental health problems, such as PTSD. Services that fail to address this key issue risk re-traumatising individuals through treatment $(56,71)$, which will serve as a further barrier to recovery. Trauma therapies, such as EMDR (Eye Movement Desensitisation and Reprocessing) have a strong evidence base (72) but may only be effective when an individual has sufficient personal resources and stability to undertake what is very challenging therapeutic work. The presence of trauma and stigma and the impact these have on service users' abilities to be able to engage with treatment, social support systems and their wider communities needs to be considered at all stages of treatment; without adequate support some may never be ready to address the underlying issues that have resulted in their problematic drug use. As such, individuals may find themselves trapped in a cycle of trauma, drug use, stigma, shame and guilt (figure 3). 


\section{FACTORS INFLUENCING RECOVERY IN OST}

\section{Strengths and limitations}

To our knowledge, this is the first use of the Socioecological Model (SEM) as a framework for visualising the complex nature of recovery in OST and the interaction of different factors at different levels. Complex systems approaches such as this are increasingly being used in the development of complex public health interventions as they situate individual behaviour change within a wider social and environmental context (17-19). Further, qualitative evidence synthesis is an important first step in developing complex health interventions (73).

Previous work (7) focussed on barriers to recovery in long-term (4+ years) methadone maintenance clients. By widening the scope to include facilitators and short-term treatment, we have built a more complete picture of the experience of recovery in OST and have synthesised the findings of a further 30 studies.

As with the previous review (7), one limitation was that the majority of studies were carried out either in the USA or UK and we only included papers written in English. Results therefore may not be generalisable to other contexts.

\section{CONCLUSIONS/IMPLICATIONS}

Our review demonstrates the highly complex nature of recovery within OST. We suggest that interventions developed to improve outcomes in this population must address this complexity. OST service users do not exist in a social and political vacuum; policies that ignore the individuality of service users and fail to accommodate their ranging and shifting needs may increase their stigmatisation. Equally, focussing all resources on tackling intrapersonal determinants of recovery may increase stigma, by placing blame on the service user whilst failing to address the wider social and environmental influences that hamper any individual efforts to achieve recovery.

\section{ACKNOWLEDGEMENTS}

We would like to thank Sarah Herring, Specialist Subject Librarian for her invaluable help in formulating the search strategy. Thanks also to Jon Shorrock, Area Services Manager, Avon and Wiltshire Mental Health Partnership (AWP), Specialist Drug and Alcohol Services for 
highlighting the need for the work; and to Dr Alice Malpass \& Dr Christie Cabral, Bristol Medical School for their advice with qualitative evidence synthesis methodology.

Victoria Carlisle's PhD is funded by the National Institute for Health Research, School for Public Heath Research (NIHR, SPHR).

Jo Kesten is partly funded by National Institute for Health Research Applied Research Collaboration West (NIHR ARC West) at University Hospitals Bristol NHS Foundation Trust and NIHR Health Protection Research Unit in Behavioural Science and Evaluation at University of Bristol.

Matthew Hickman acknowledges support from the NIHR Health Protection Research Unit in Behavioural Science and Evaluation at University of Bristol.

Kyla Thomas is funded by a National Institute for Health Research (NIHR) Postdoctoral Fellowship- PDF-2017-10-068 for this research project.

Prianka Padmanathan's PhD Clinical Fellowship is funded by the MRC Addiction Research Clinical Training programme (MR/N00616X/1). 


\section{REFERENCES}

1. United Kingdom Country Drug Report 2019 | www.emcdda.europa.eu [Internet]. [cited 2020 Jul 17]. Available from: https://www.emcdda.europa.eu/countries/drugreports/2019/united-kingdom_en

2. Cornish R, Macleod J, Strang J, Vickerman P, Hickman M. Risk of death during and after opiate substitution treatment in primary care: prospective observational study in UK General Practice Research Database. BMJ. 2010 Oct;341:c5475-c5475.

3. Degenhardt L, Grebely J, Stone J, Hickman M, Vickerman P, Marshall BDL, et al. Global patterns of opioid use and dependence: harms to populations, interventions, and future action. The Lancet. 2019 Oct 26;394(10208):1560-79.

4. Degenhardt L, Wolfe D, Hall W, Hickman M, Chang J, Bruneau J, et al. Strategies to reduce drug-related harm: responding to the evidence base. The Lancet. 2019 Oct 26;394(10208):1490-3.

5. Hickman M, Steer C, Tilling K, Lim AG, Marsden J, Millar T, et al. The impact of buprenorphine and methadone on mortality: a primary care cohort study in the United Kingdom. Addiction. 2018 Aug;113(8):1461-76.

6. Mukandavire C, Low A, Mburu G, Trickey A, May MT, Davies CF, et al. Impact of opioid substitution therapy on the HIV prevention benefit of antiretroviral therapy for people who inject drugs. AIDS. 2017 May;31(8):1181-90.

7. Notley C, Blyth A, Maskrey V, Craig J, Holland R. The Experience of Long-Term Opiate Maintenance Treatment and Reported Barriers to Recovery: A Qualitative Systematic Review. Eur Addict Res. 2013;19(6):287-98.

8. Home Office. 2017 Drug Strategy. 2017; Available from: https://www.gov.uk/government/uploads/system/uploads/attachment_data/file/628148/ Drug_strategy_2017.PDF

9. Volkow ND, Collins FS. The Role of Science in Addressing the Opioid Crisis. N Engl J Med. 2017 Jul;377(4):391-4.

10. Carlisle V, Kesten J, Maynard O, Padmanathan P, Thomas K, Hickman M. Barriers to and facilitators of completing opioid substitution treatment (OST) and recovering from opioid dependency: a meta-ethnography [Internet]. PROSPERO. 2019. Available from: https://www.crd.york.ac.uk/prospero/display_record.php?RecordID=120367

11. Methley AM, Campbell S, Chew-Graham C, McNally R, Cheraghi-Sohi S. PICO, PICOS and SPIDER: a comparison study of specificity and sensitivity in three search tools for qualitative systematic reviews. BMC Health Serv Res. 2014 Dec;14(1):579_ 579 .

12. The University of York. ISSG Search Filters Resource [Internet]. 2018. Available from: https://sites.google.com/a/york.ac.uk/issg-search-filters-resource/home 
13. Noblit GW, Hare RDR. Meta-ethnography: Synthesizing qualitative studies. Qualitative research methods series Newbury Park. California: SAGE Publications; 1988.

14. Toye F, Seers K, Allcock N, Briggs M, Carr E, Barker K, et al. Meta-ethnography 25 years on: challenges and insights for synthesising a large number of qualitative studies [Internet]. Vol. 14, BMC Medical Research Methodology. 2014 p. 80-80. Available from: http://www.biomedcentral.com/1471-2288/14/80

15. Thomas J, Harden A. Methods for the thematic synthesis of qualitative research in systematic reviews. 2008; Available from: http://www.biomedcentral.com/1471$2288 / 8 / 45$

16. McLeroy KR, Bibeau D, Steckler A, Glanz K. An ecological perspective on health promotion programs. Health Educ Q. 1988;15(4):351-77.

17. Hawe P. Lessons from complex interventions to improve health. Annu Rev Public Health. 2015;36:307-23.

18. Hawe P, Shiell A, Riley T. Theorising interventions as events in systems. In: American Journal of Community Psychology. John Wiley \& Sons, Ltd; 2009. p. 267-76.

19. Moore GF, Evans RE, Hawkins J, Littlecott H, Melendez-Torres GJ, Bonell C, et al. From complex social interventions to interventions in complex social systems: Future directions and unresolved questions for intervention development and evaluation. Evaluation. 2019 Jan;25(1):23-45.

20. Gelpi-Acosta C. Challenging biopower: 'Liquid cuffs' and the 'Junkie' habitus. Drugs Abingdon Engl. 2014;22(3):248-54.

21. Moran L, Keenan E, Elmusharaf K. Barriers to progressing through a methadone maintenance treatment programme: perspectives of the clients in the Mid-West of Ireland's drug and alcohol services. BMC Health Serv Res. 2018;18(1):911-911.

22. Smith ML, Rosen D. Mistrust and self-isolation: Barriers to social support for older adult methadone clients. [References]. J Gerontol Soc Work Vol. 2009;52(7):653-67.

23. Vigilant LG. 'I don't have another run left with if': Ontological security in illness narratives of recovering on methadone maintenance. Deviant Behav. 2005 Sep;26(5):399-416.

24. Nettleton S, Neale J, Pickering L. 'I don't think there's much of a rational mind in a drug addict when they are in the thick of it': towards an embodied analysis of recovering heroin users. Sociol Health Illn. 2011;33(3):341-55.

25. Gronnestad TE, Sagvaag H. Stuck in limbo: illicit drug users' experiences with opioid maintenance treatment and the relation to recovery. Int J Qual Stud Health Well-Being. 2016;11:31992-31992.

26. Neale J. Understanding drug-using clients' views of substitute prescribing. Br J Soc Work Vol. 1999;29(1):127-45. 
27. Nettleton S, Neale J, Pickering L. 'I just want to be normal': An analysis of discourses of normality among recovering heroin users. [References]. Health Interdiscip J Soc Study Health Illn Med Vol. 2012;17(2):174-90.

28. Pickett ND, Domene JF. Counselling utilization experiences among methadone maintenance treatment clients in rural and small urban communities. [References]. Can J Couns Psychother Vol. 2014;48(1):22-37.

29. Notley C, Blyth A, Maskrey V, Pinto H, Holland R. Exploring the Concepts of Abstinence and Recovery Through the Experiences of Long-Term Opiate Substitution Clients. Subst Abuse. 2015 Apr;36(2):232-9.

30. Järvinen M. Approaches to methadone treatment: harm reduction in theory and practice. Sociol Health Illn. 2008 Nov;30(7):975-91.

31. Van Hout MC, Bingham T. Methadone maintenance and Special Community Employment schemes: A study of Irish participants' views. J Vocat Rehabil. 2012;37(1):63-73 11p.

32. Mitchell SG, Morioka R, Reisinger HS, Peterson JA, Kelly SM, Agar MH, et al. Redefining retention: recovery from the patient's perspective. J Psychoact Drugs. 2011;43(2):99-107.

33. Strike C, Millson M, Hopkins S, Smith C. What is low threshold methadone maintenance treatment? Int J Drug Policy. 2013;24(6):e51-6.

34. Rance J, Treloar C. 'Not just methadone Tracy': Transformations in service-user identity following the introduction of hepatitis $\mathrm{C}$ treatment into Australian opiate substitution settings. [References]. Addict Vol. 2014;109(3):452-9.

35. Van Hout MC, Bingham T. Service stakeholders' perspectives on methadone maintenance treatment, Special Community Employment schemes and client recovery pathways. [References]. J Vocat Rehabil Vol. 2014;40(1):49-58.

36. Arnold RM, Avants SK, Margolin A, Marcotte D. Patient attitudes concerning the inclusion of spirituality into addiction treatment. J Subst Abuse Treat. 2002;23(4):319_ 26.

37. Redden SM, Tracy SJ, Shafer MS. A metaphor analysis of recovering substance abusers' sensemaking of medication-assisted treatment. [References]. Qual Health Res Vol. 2013;23(7):951-62.

38. Glickman L, Galanter M, Dermatis H, Dingle S. Recovery and spiritual transformation among peer leaders of a modified methadone anonymous group. J Psychoact Drugs Vol. 2006;38(4):531-3.

39. Cordella B, Greco F, Elia P, Varazi M. Lifelong maintenance treatment or 'positive' dropout? J Subst Use. 2017;22(4):372-6.

40. De Maeyer J, Vanderplasschen W, Camfield L, Vanheule S, Sabbe B, Broekaert E. A good quality of life under the influence of methadone: A qualitative study among opiate-dependent individuals. Int J Nurs Stud. 2011 Oct;48(10):1244-57. 
41. Latham L. Methadone treatment in Irish general practice: Voices of service users. Ir $\mathbf{J}$ Psychol Med. 2012;29(3):147-56.

42. Lilly R, Quirk A, Rhodes T, Stimson GV. Juggling multiple roles: Staff and client perceptions of keyworker roles and the constraints on delivering counselling and support services in methadone treatment. [References]. Addict Res Vol. 1999;7(4):26789.

43. Ayres RM, Eveson L, Ingram J, Telfer M. Treatment experience and needs of older drug users in Bristol, UK. J Subst Use. 2012;17(1):19-31.

44. Neale J, Nettleton S, Pickering L. Does recovery-oriented treatment prompt heroin users prematurely into detoxification and abstinence programmes? Qualitative study. Drug Alcohol Depend. 2013;127(1):163-9.

45. O’Byrne P, Jeske Pearson C. Methadone maintenance treatment as social control: Analyzing patient experiences. Nurs Inq. 2018;e12275-e12275.

46. Van Hout MC, Bingham T. A qualitative study of prescribing doctor experiences of methadone maintenance treatment. [References]. Int J Ment Health Addict Vol. 2014;12(3):227-42.

47. Notley C, Holland R, Maskrey V, Nagar J, Kouimtsidis C. Regaining control: The patient experience of supervised compared with unsupervised consumption in opiate substitution treatment. Drug Alcohol Rev. 2014 Jan;33(1):64-70.

48. Gourlay J, Ricciardelli L, Ridge D. Users' Experiences of Heroin and Methadone Treatment. Subst Use Misuse. 2005 Jan;40(12):1875-82.

49. Le PP, Braunack-Mayer A. Perspectives on privacy in the pharmacy: The views of opioid substitution treatment clients. Res Soc Adm Pharm. 2019 Aug;15(8):1021-6.

50. McPhee I, Brown A, Martin C. Stigma and perceptions of recovery in Scotland: a qualitative study of injecting drug users attending methadone treatment. Drugs Alcohol Today. 2013;13(4):244-57.

51. O'Conner K, Rosen D. 'You're nothing but a junkie': multiple experiences of stigma in an aging methadone maintenance population. J Soc Work Pract Addict. 2008;8(2):24464.

52. Vigilant LG. 'I am still suffering': The dilemma of multiple recoveries in the lives of methadone maintenance patients. [References]. Sociol Spectr Vol. 2008;28(3):278-98.

53. Felitti VJ, Anda RF, Nordenberg D, Williamson DF, Spitz AM, Edwards V, et al. Relationship of Childhood Abuse and Household Dysfunction to Many of the Leading Causes of Death in Adults: The Adverse Childhood Experiences (ACE) Study. Am J Prev Med. 2019 Jun;56(6):774-86.

54. Bartoszko A. The Lethal Burden of Survival: Making New Subjects at Risk and the Paradoxes of Opioid Substitution Treatment in Norway. Contemp Drug Probl. 2018 Sep;45(3):208-26. 
55. Stein MD, Conti MT, Kenney S, Anderson BJ, Flori JN, Risi MM, et al. Adverse childhood experience effects on opioid use initiation, injection drug use, and overdose among persons with opioid use disorder. Drug Alcohol Depend. 2017 Oct;179:325-9.

56. Johnstone L, Boyle M. The Power Threat Meaning Framework: An Alternative Nondiagnostic Conceptual System. J Humanist Psychol. 2018 Aug;002216781879328002216781879328 .

57. Dorahy MJ, Corry M, Shannon M, Webb K, McDermott B, Ryan M, et al. Complex trauma and intimate relationships: The impact of shame, guilt and dissociation. J Affect Disord. 2013 May;147(1-3):72-9.

58. Järvinen M, Andersen D. The making of the chronic addict. Subst Use Misuse. 2009 May;44(6):865-85.

59. Goffman E. Stigma: Notes on The Management of Spoiled Identity. New York: Simon and Shuster; 1963.

60. Ashford RD, Brown AM, Canode B, McDaniel J, Curtis B. A Mixed-Methods Exploration of the Role and Impact of Stigma and Advocacy on Substance Use Disorder Recovery. Alcohol Treat Q. 2019 Oct;37(4):462-80.

61. Barry CL, McGinty EE, Pescosolido BA, Goldman HH. Stigma, discrimination, treatment effectiveness, and policy: Public views about drug addiction and mental illness. Psychiatr Serv. 2014 Oct;65(10):1269-72.

62. Flanagan O. The Shame of Addiction. Front Psychiatry. 2013 Oct;4(OCT):120-120.

63. Woods JS, Joseph H. Reducing Stigma Through Education to Enhance MedicationAssisted Recovery. J Addict Dis. 2012 Jul;31(3):226-35.

64. Antoniou T, Ala-Leppilampi K, Shearer D, Parsons JA, Tadrous M, Gomes T. "Like being put on an ice floe and shoved away": A qualitative study of the impacts of opioidrelated policy changes on people who take opioids. Int J Drug Policy. 2019 Apr;66:1522.

65. Kennedy-Hendricks A, Busch SH, McGinty EE, Bachhuber MA, Niederdeppe J, Gollust SE, et al. Primary care physicians' perspectives on the prescription opioid epidemic. Drug Alcohol Depend. 2016 Aug;165:61-70.

66. McCradden MD, Vasileva D, Orchanian-Cheff A, Buchman DZ. Ambiguous identities of drugs and people: A scoping review of opioid-related stigma. Int J Drug Policy. 2019 Dec;74:205-15.

67. Link BG, Phelan JC. Conceptualizing Stigma. Annu Rev Sociol. 2001 Aug;27(1):36385.

68. Farr M, Davies R, Bagnall D, Brangan E, Andrews H. A map of resources for coproducing research in health and social care: A guide for researchers, members of the public and social care practitioners. Bristol; 2020. 
69. Ocloo J, Matthews R. From tokenism to empowerment: Progressing patient and public involvement in healthcare improvement. BMJ Qual Saf. 2016 Aug;25(8):626-32.

70. Staniszewska S, Denegri S, Matthews R, Minogue V. Reviewing progress in public involvement in NIHR research: Developing and implementing a new vision for the future. BMJ Open. 2018 Jul;8(7):e017124-e017124.

71. Read J, Harper DavidJ. The Power Threat Meaning Framework: Addressing Adversity, Challenging Prejudice and Stigma, and Transforming Services. J Constr Psychol. 2020 Jun;1-14.

72. Roberts N, Roberts P, Jones N, Bisson J. Psychological therapies for post-traumatic stress disorder and comorbid substance use disorder [Internet]. Cohrane Database of Systematic Reviews. 2016. Available from:

https://www.cochranelibrary.com/cdsr/doi/10.1002/14651858.CD010204.pub2/abstract

73. Yardley L, Morrison L, Bradbury K, Muller I. The person-based approach to intervention development: Application to digital health-related behavior change interventions. J Med Internet Res. 2015 Jan;17(1):e30-e30.

74. Smith ML, Rosen D. Mistrust and self-isolation: barriers to social support for older adult methadone clients. J Gerontol Soc Work. 2009;52(7):653-67. 


\section{FACTORS INFLUENCING RECOVERY IN OST}

\section{FIGURES AND TABLES}

\section{Table 1 Characteristics of included studies}

\begin{tabular}{|c|c|c|c|c|}
\hline Reference & Location & Overview of study & Population & Analysis \\
\hline Arnold et al (2002) & USA & Acceptability of a spirituality-based intervention for HIV-positive service users in OST. & Service users & Unclear \\
\hline Ayres et al (2012) & UK & $\begin{array}{l}\text { Barriers to and facilitators of older OST clients ( }>55) \text { attending recovery groups outside of } \\
\text { shared-care. }\end{array}$ & Service users & Inductive Thematic Analysis \\
\hline Bartoszko (2018) & Norway & The way that negative experiences of OST contribute to early discharge from treatment. & $\begin{array}{l}\text { Service users \& service } \\
\text { providers }\end{array}$ & Thematic (unspecified) \\
\hline Cordella et al (2017) & Italy & $\begin{array}{l}\text { Differing attitudes of those choosing to stay in long-term treatment and those that have } \\
\text { chosen to leave (and have maintained abstinence long-term) }\end{array}$ & Service users & Content analysis \\
\hline De Maeyer et al. (2011) & Belgium & Perceptions of quality of life in OST service users & Service users & Interpretive Thematic Analysis \\
\hline Ekendahl (2011) & Sweden & The use of service provider discourses in their legitimisation of OST & Service providers & Discourse analysis \\
\hline Gelpi-Acosta (2014) & USA & Issues of treatment adherence in OST & Service users & $\begin{array}{l}\text { Grounded theory (Glaser \& } \\
\text { Strauss) }\end{array}$ \\
\hline Glickman et al (2006) & USA & Recovery experiences of peer leaders in a methadone anonymous group & Service users & Unclear \\
\hline $\begin{array}{l}\text { Gronnestad \& Sagvaag } \\
\text { (2016) }\end{array}$ & Norway & The effect that the illicit drug scene has on service user experiences of OST & Service users & Phenomenological Hermenutical \\
\hline Gourlay et al. (2005) & Australia & Exploration of personal resources that contribute to more positive experiences of OST & Service uses & Grounded theory \\
\hline Jarvinen (2008) & Denmark & $\begin{array}{l}\text { Attitudes and experiences of harm reduction and abstinence in OST } \\
\text { service users \& staff }\end{array}$ & $\begin{array}{l}\text { Service users \& service } \\
\text { providers }\end{array}$ & Narrative \\
\hline $\begin{array}{l}\text { Jarvinen \& Andersen } \\
(2009)\end{array}$ & Denmark & $\begin{array}{l}\text { Chronic disease discourses of addiction and their influence on service users' experiences of } \\
\text { treatment. }\end{array}$ & Service users & Narrative \\
\hline
\end{tabular}




\begin{tabular}{|c|c|c|c|c|}
\hline Table 1. (continued) & Location & Overview of study & Population & Analysis \\
\hline $\begin{array}{l}\text { Kondoni \& Kouimtsidis } \\
\text { (2017) }\end{array}$ & UK & A patient-centred evaluation of the reasons for not completing OST & Service users & Grounded theory \\
\hline Latham (2012) & Ireland & The ways that service users experience the implementation of OST in General Practice & Service users & $\begin{array}{l}\text { Colazzi's Existential } \\
\text { Phenomenological Analysis }\end{array}$ \\
\hline $\begin{array}{l}\text { Le \& Braunack-Mayer } \\
(2019)\end{array}$ & Australia & OST service user experiences of privacy in a pharmacy setting & Service users & Framework analysis \\
\hline Lilly et al (1999) & UK & $\begin{array}{l}\text { Staff and service user experiences of ability to provide counselling and support services } \\
\text { within a keyworker role }\end{array}$ & $\begin{array}{l}\text { Service users and service } \\
\text { providers }\end{array}$ & $\begin{array}{l}\text { Grounded Theory (Glaser \& } \\
\text { Strauss) }\end{array}$ \\
\hline McPhee et al (2013) & UK (Scotland) & Service user experiences of stigma as an injecting drug user & Service users & Interpretive Thematic Analysis \\
\hline Mitchell et al (2011) & USA & $\begin{array}{l}\text { Service user experiences of being discharged prematurely from treatment and subsequent re- } \\
\text { entry }\end{array}$ & Service users & $\begin{array}{l}\text { Grounded Theory (Strauss \& } \\
\text { Corbin) }\end{array}$ \\
\hline Moran et al (2018) & Ireland & $\begin{array}{l}\text { Exploring reasons for why a large proportion of OST service uesrs are 'stuck' in the high-risk, } \\
\text { specialist clinical setting and not transferred to GP care }\end{array}$ & Service users & Thematic Analysis \\
\hline Neale (1999) & UK (Scotland) & Drug users' experiences and expectations of obtaining OST scripts & Service users & $\begin{array}{l}\text { Code and retrieve' (inductive, } \\
\text { based on Glaser \& Strauss). }\end{array}$ \\
\hline Neale et al (2013) & UK & Possible negative consequences of recovery-orientated treatment & Service users & Framework analysis \\
\hline Nettleton et al (2011) & UK & Embodied aspects of recovery from heroin dependency & Service users & Unclear \\
\hline Nettleton et al (2012) & UK & Exploring service users' goal of 'normality' though the lens of Foucauldian theory & Service users & Discourse Analysis \\
\hline Notley et al (2014) & UK & Service user experiences of supervised consumption in a UK pharmacy setting & $\begin{array}{l}\text { Service users and service } \\
\text { providers }\end{array}$ & Grounded theory \\
\hline Notley et al (2015) & UK & Service user experiences of long-term OST & Service users & $\begin{array}{l}\text { Grounded theory (Glaser \& } \\
\text { Strauss) }\end{array}$ \\
\hline
\end{tabular}




\section{FACTORS INFLUENCING RECOVERY IN OST}

\begin{tabular}{|c|c|c|c|c|}
\hline Table. 1 (continued) & Location & Overview of study & Population & Analysis \\
\hline $\begin{array}{l}\text { O’Byrne \& Pearson } \\
\text { (2018) }\end{array}$ & Canada & Service user experiences of discontinuing treatment before twelve months & Service users & Thematic Analysis \\
\hline $\begin{array}{l}\text { O’Connor \& Rosen } \\
\text { (2008) }\end{array}$ & USA & $\begin{array}{l}\text { Service user experiences of stigma and how stigma influences retention in treatment and } \\
\text { engagement with mental health services }\end{array}$ & Service users & Content Analysis \\
\hline $\begin{array}{l}\text { Pickett \& Domene } \\
\text { (2014) }\end{array}$ & Canada & The utilization of counselling services by OST service users & Service users & Thematic Analysis \\
\hline Rance \& Treloar (2014) & Australia & Identity transformation experiences of OST service users & $\begin{array}{l}\text { Service users and service } \\
\text { providers }\end{array}$ & Adaptive coding \\
\hline Redden et al (2013) & USA & Metaphors used by OST service users to describe their experiences of treatment & Service users & Discourse analysis \\
\hline Smith \& Rosen (2009) & USA & Older clients' experiences of utilising social support & Service users & Content analysis \\
\hline Strike et al (2013) & Canada & $\begin{array}{l}\text { Client experiences of 'low-threshold' (for those without abstinence as a goal) OST treatment } \\
\text { in Canada }\end{array}$ & $\begin{array}{l}\text { Service users and service } \\
\text { providers }\end{array}$ & $\begin{array}{l}\text { Iterative coding (Corbin \& } \\
\text { Strauss) }\end{array}$ \\
\hline $\begin{array}{l}\text { Van Hout \& Bingham } \\
\text { (2012) }\end{array}$ & Ireland & OST client experiences of special community employment schemes in Ireland & $\begin{array}{l}\text { MMT service users in a } \\
\text { community employment } \\
\text { scheme. }\end{array}$ & Thematic and content analysis \\
\hline $\begin{array}{l}\text { Van Hout \& Bingham } \\
\text { (2014a) }\end{array}$ & Ireland & Stakeholder experiences of special community employment schemes in Ireland & Service providers & Thematic analysis \\
\hline $\begin{array}{l}\text { Van Hout \& Bingham } \\
\text { (2014b) }\end{array}$ & Ireland & $\begin{array}{l}\text { Doctor experiences of OST prescribing, therapeutic alliance with service users and treatment } \\
\text { pathways }\end{array}$ & Service providers & Thematic analysis \\
\hline Vigilant (2005) & USA & Service user experiences of the meanings and practice of recovery & Service users & Not clear \\
\hline Vigilant (2008) & USA & OST service user experiences of the concepts of addiction and recovery & Service users & Grounded theory (Chamaz) \\
\hline
\end{tabular}




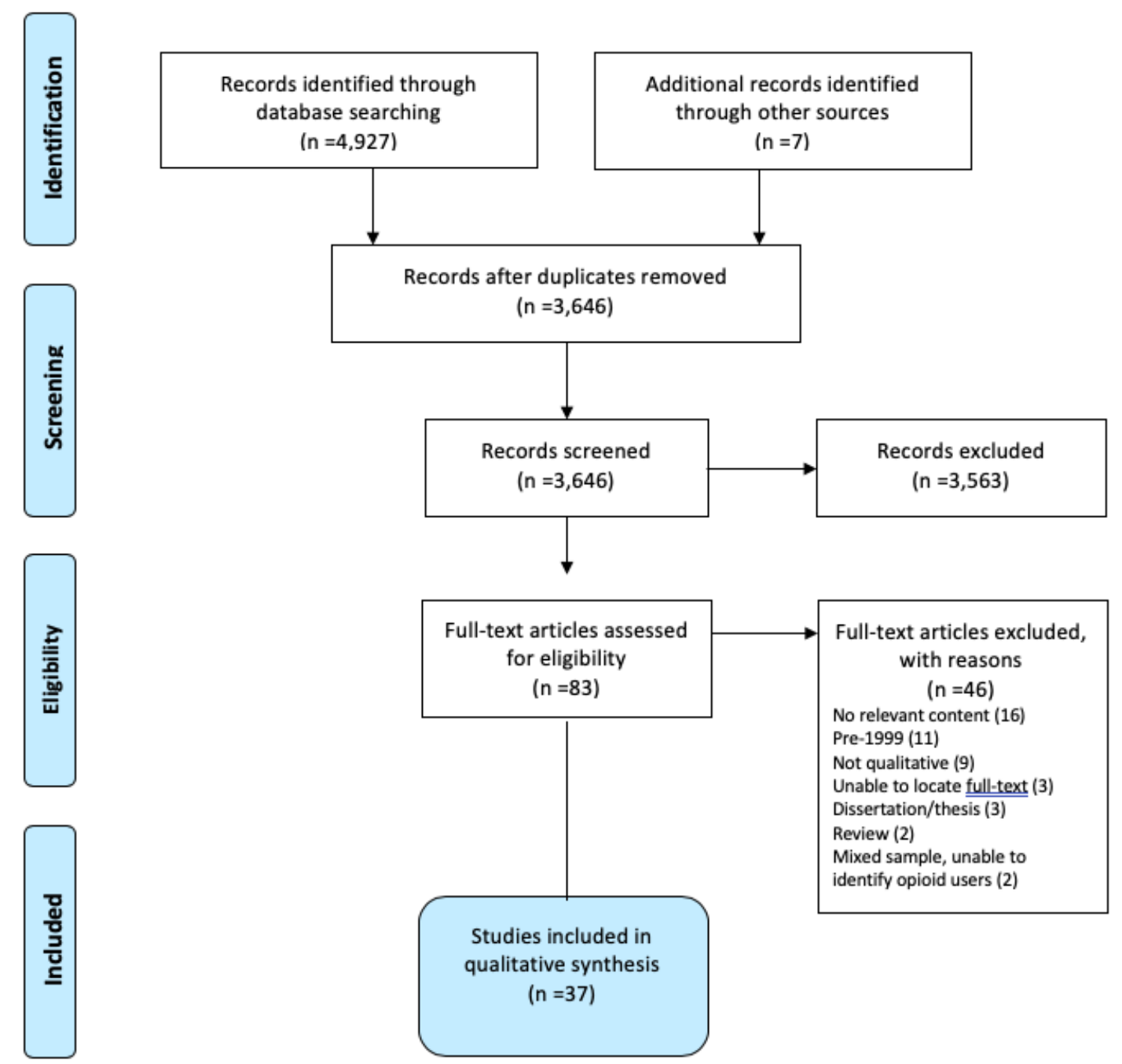

Figure 1: PRISMA flow diagram 


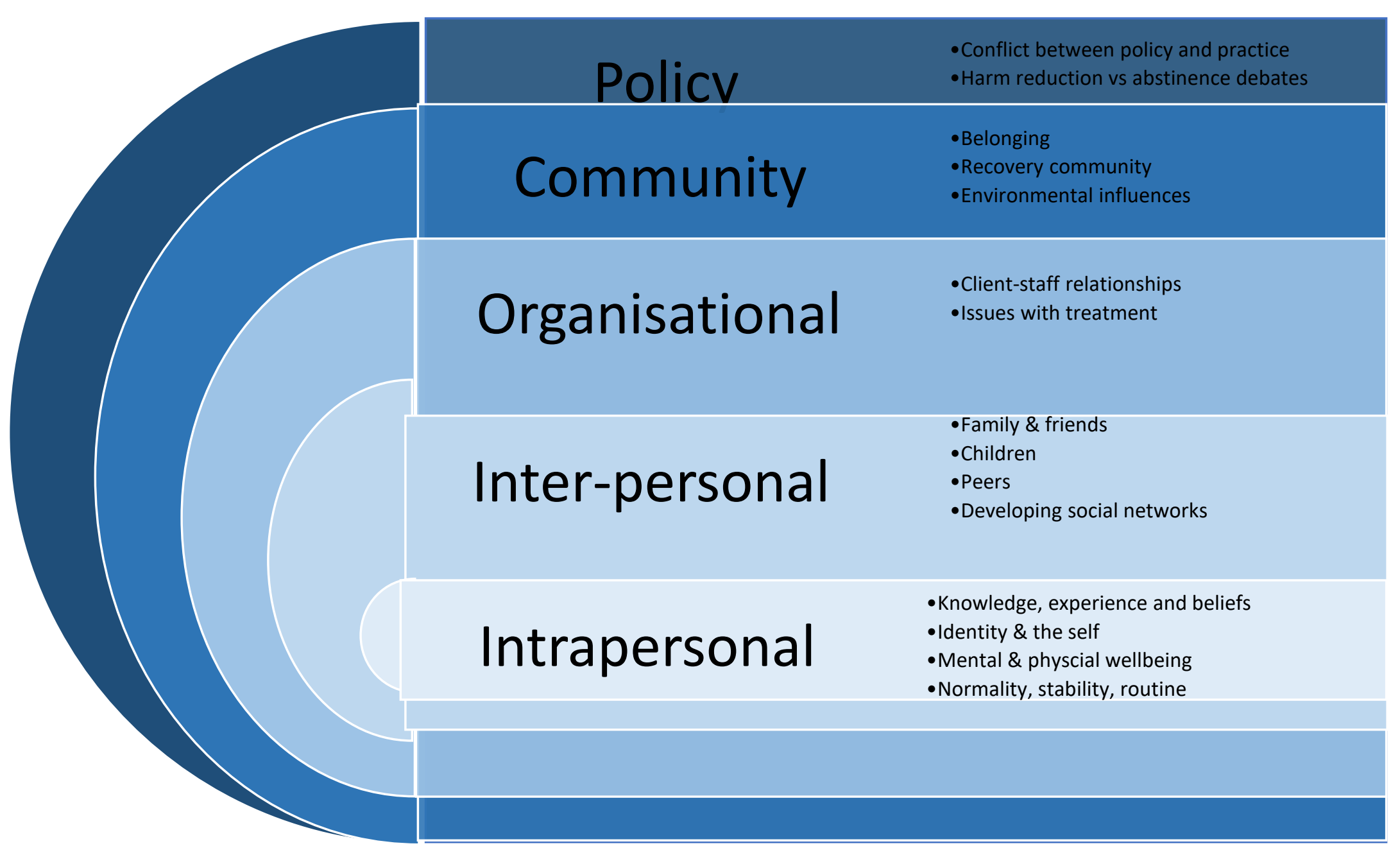

Figure 2: Descriptive themes and their mapping onto the socioecological model. Stigma permeates all levels of the system. 


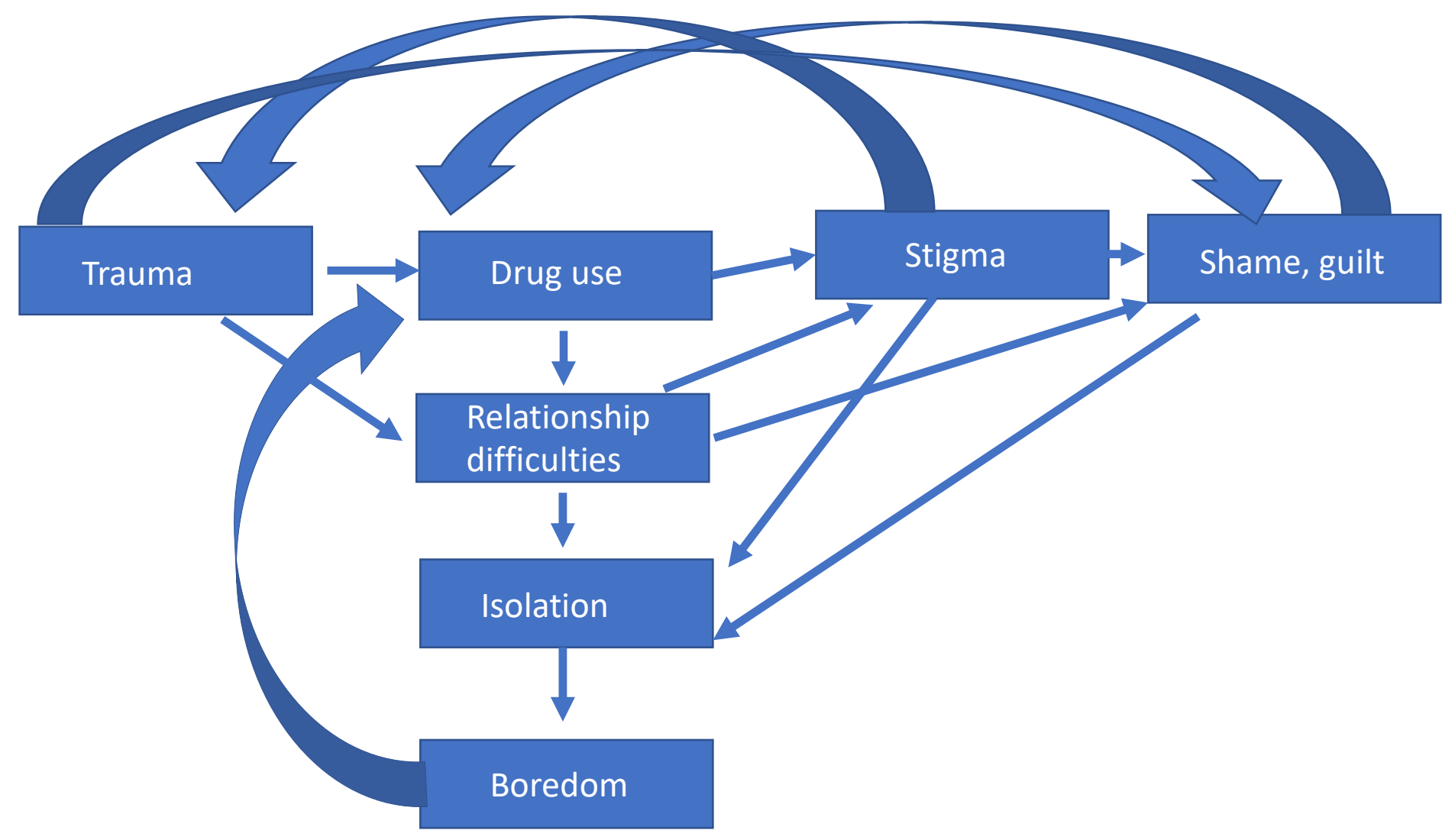

Figure 3: The complex and interacting relationship between key factors that influence recovery in OST. 